\title{
POUNDING CONTROL OF BASE ISOLATED STRUCTURES*
}

\author{
Sayed S. Abd-elsalam, Atef E. Bakry, Hanaa E. Abd-El-Mottaleb, and Ayman A. M. Hussain+ \\ Structural Eng. Dept., Faculty of Engineering, Zagazig University, Egypt
}

\begin{abstract}
The most important property of a base-isolation system is to make the base more flexible than the elements of the superstructure, but it must still be stiff enough to resist typical pounding forces, wind loadings, and similar low-amplitude horizontal forces. However, the potential consequences of earthquake-induced poundings on seismically isolated buildings can be much more substantial, and, thus, should be assessed. This paper investigates, through numerical simulations, the effects of potential pounding incidences on the seismic response of a typical seismically isolated building and to make the control system with hydraulic viscous damper to reduce the transmitted energy. A specialized software application has been developed in order to efficiently perform numerical simulations and parametric studies on the control system. The effects of certain parameters, such as the post-pre stiffness ratio, plastic shear capacity of the viscous and damper the characteristics of the adjacent structures have been investigated using the developed software. The simulations have revealed that the viscous damper decreases the total displacement and the total transmitted energy. Also the best case of the hydraulic dampers when the elasto-plastic with zero plastic stiffness.
\end{abstract}

KEY WORDS: Base isolation, pounding, control, adjacent buildings

\section{CONTRÔLE DE BASE PILONNANT STRUCTURES ISOLEES}

\section{RÉSUMÉ}

La propriété la plus importante d'un système de base-isolement est de rendre la base plus flexible que les éléments de la superstructure, mais elle doit toujours être suffisamment rigide pour résister aux forces typiques battant, charges dues au vent, et même de faible amplitude des forces horizontales. Cependant, les conséquences potentielles du tremblement de terre induits sur les bâtiments poundings sismiquement isolées peuvent être beaucoup plus importante, et, par conséquent, devrait être évaluée. Cet article étudie, à travers des simulations numériques, les effets du potentiel des incidences à cogner sur la réponse sismique d'un bâtiment typique sismiquement isolées et de rendre le système de contrôle avec amortisseur visqueux hydraulique afin de réduire l'énergie transmise. Un logiciel spécialisé a été développé afin de s'acquitter efficacement des simulations numériques et des études paramétriques sur le système de contrôle. Les effets de certains paramètres, tels que le ratio de rigidité post-pré, la capacité de cisaillement plastique de l'amortisseur visqueux et les caractéristiques des structures adjacentes ont été étudiés en utilisant le logiciel développé. Les simulations ont révélé que l'amortisseur visqueux diminue le déplacement total et l'énergie totale transmise. Aussi le meilleur des cas des amortisseurs hydrauliques lorsque le comportement élasto-plastique avec zéro rigidité plastique.

MOTS CLES: isolement de base, pilage, le contrôle, les bâtiments adjacents
* Received: 8/5/2011, Accepted: 22/6/2011 (Original Paper)
+ Contact Author (+20 101040132) 


\section{INTRODUCTION}

During earthquakes, adjacent buildings with insufficient separation distance often collide with each other. The most direct way to reduce or avoid pounding is to provide an adequate separation distance between the buildings. For adjacent buildings without base isolation, the International Building Code (IBC) [1] specifies the minimum distance to be the square root of the sum of the squares (SRSS) of the individual building displacements. But in case of base isolated buildings, it specifies the gap between the buildings as the sum of the maximum sliding displacements and the maximum building deflections. Thus, in all over the world many buildings are often built close to each other as in the case of residential building complexes or in downtown of metropolitan cities where the cost of land is high. And however, since the size of the seismic gap, which is provided around a seismically isolated building to facilitate the large relative displacements at the isolation level, is usually finite due to practical limitations, poundings of the building with adjacent structures may occur during strong earthquakes. Therefore, it is important to be aware of how potential poundings of seismically isolated buildings with adjacent structures may affect the effectiveness of seismic isolation (Komodromos [2]).

Anagnostopoulos [3] modeled adjacent buildings as single degree of freedom lumped mass systems with a spring and dashpot connection to simulate the impact. Chau and Wei [4] studied adjacent buildings as single degree of freedom systems with non- linear Hertzian impacts, taken into account by applying conservation of momentum during impact. Muthukumar and DesRoches, 2006[5] makes a Comparison of Numerical Models of Impact Force for Simulation of Earthquake-Induced Structural
Pounding, The aim of the present paper is to check the accuracy of three pounding force numerical models, such as: the linear viscoelastic model, the non-linear elastic model following the Hertz law of contact and the non-linear viscoelastic model.

Nawawi, et al., [6] studied the reduction of pounding responses of bridges girders with soil-structure interaction effects to spatial near-source ground motions. They address a possible measure for reducing the pounding potential between two identical adjacent bridge girders. The using of spring and viscous damper in the investigation the influence of the spatially varying ground excitation and the soil-structure interaction are considered. They find that the reduction measure increases significantly the damping of the bridge structures, and consequently reduces the girder pounding occurrences. Orlando, et al., [7] studied a numerical investigation of a variable damping semiactive device for the mitigation of the seismic response of adjacent structures. And find that there is one way to overcome the effect of pounding is to couple the structures through elastic or damping elements. This article examines the use of a new variable damping device as a coupling element.

As the structures vibrate due to the ground motion, the lower end is moved up and down by means of an actuator. By changing the orientation of the dampers, the effective damping in the two structures can be changed in time in an appropriate manner to minimize the response. Anew control law is used to calculate the optimal position of the dampers. The algorithm, referred to as $\mathrm{Q}_{\mathrm{v}}$, is a variation of the Instantaneous Optimal Control and it is based on the minimization of a performance index $\mathrm{J}$ quadratic in the state vector, the control force vector, and a vector of absolute velocities measured at selected points. The algorithm includes a generalized LQR scheme where penalties are 
imposed on the state vector, on the control vector, and on the absolute velocity vector through three predefined matrices. A numerical simulation is used to verify the performance of the proposed protective system in reducing the seismic response to a series of historic earthquakes. The results show that the proposed device is able not only to eliminate the pounding effects but also to significantly reduce the response of the individual adjacent structures. Measures for reducing the pounding effects have been investigated by many researchers. For example, introducing the shared tuned mass damper STMD that links two adjacent buildings. Their study showed that buildings with STMD could perform better than buildings with individual TMD. Westermo linked the neighboring buildings with springs and viscous dampers at possible pounding locations. The two building connected two neighboring buildings with fluid dampers at the floor levels in their investigation. Jankowski et al., [8] studied the effectiveness of different reduction measures installed between the adjacent bridge girders.

The dynamic response equations written for each building include impact forces. The resulting system of second order equations is recast as a system of first order ordinary differential equations in the state space approach for the numerical simulation and solved with MATLAB [9].

\section{THEORY AND MODELING}

One of the main aims of this study is to investigate the problem of earthquakes induced pounding between two buildings and how to reduce the effect of this phenomenon. Two adjacent base isolated buildings 2DOF with viscous damper connected the two buildings at all levels at the clearance distance between them are analyzed, in order to study the pounding control and the behavior of the adjacent buildings with change in the parameter of this connected link.

Fig. 1(a) provides a schematic diagram of two adjacent buildings $\mathrm{A}$ and $\mathrm{B}$ that include the connected damper. Also, Fig. 1(b) shows the Elastoplastic material of the connector which used in all levels of structures.
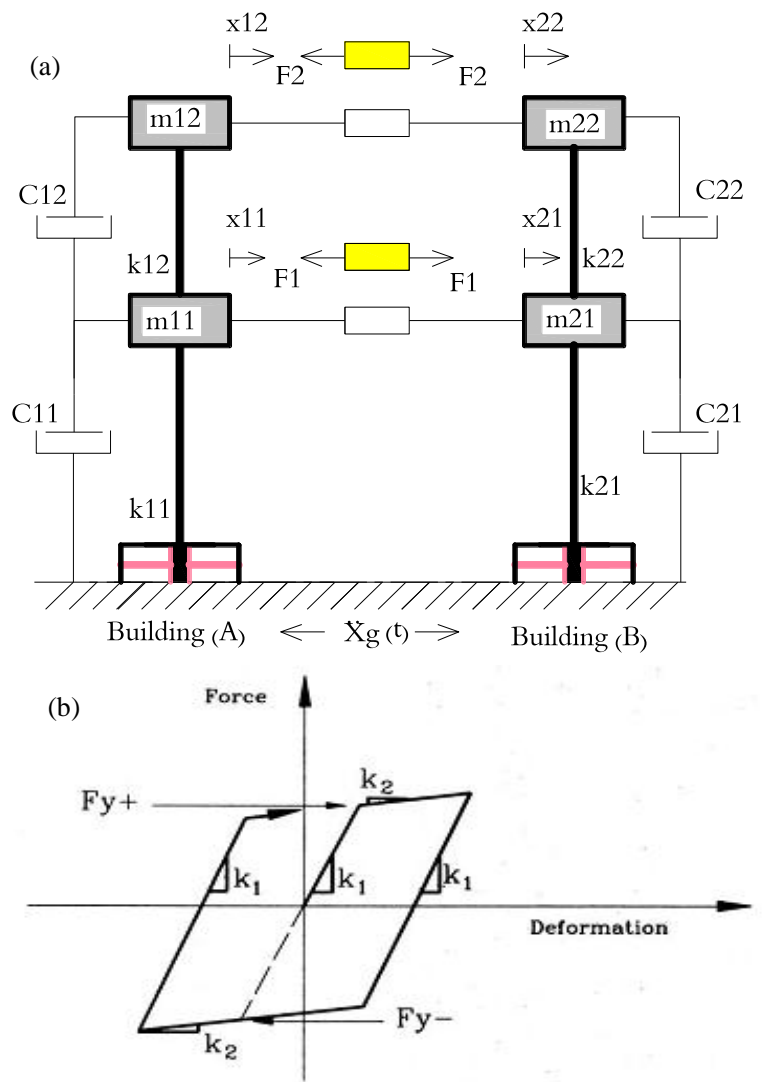

Fig. 1: (a) Schematic of the adjacent building connected with viscous damper link (b) elastoplastic material of the connector.

\subsection{Equations of Motion}

For a seismically isolated structure with base mass $m_{b}$ this equation can be written for a superstructure part for one building in this form [11]:

$$
\begin{aligned}
& M \ddot{X}^{\prime}+C \dot{X}^{\prime}+K X^{\prime}= \\
& -M R\left(\ddot{u}_{g}+\ddot{x}_{b}^{\prime}\right)
\end{aligned}
$$

where $\mathrm{R}$ is a vector that couples each degree of freedom to the ground motion, and $\mathrm{C}, \mathrm{K}$ 
and $\mathrm{M}$ are the damping, stiffness and mass matrices of the adjacent buildings, respectively. And $X^{\prime}, \dot{X}^{\prime}, \ddot{X}^{\prime}$ are the displacement, velocity and acceleration vectors of the upper stories relative to the base slab, respectively; and $\dddot{x}_{b}^{\prime}$ is the relative acceleration of the base with respect to the ground; and $\ddot{u}_{g}$ is the ground acceleration. The overall equation of motion of the isolated building [11]:

$$
\begin{gathered}
R^{T} M \ddot{X}^{\prime}+\left(\sum_{i=1}^{n} m_{j i}+m_{j b}\right) \ddot{x}_{j b}^{\prime}+c_{j b} \dot{x}_{j b}^{\prime}+k_{j b} x^{\prime} j b= \\
-\left(\sum_{i=1}^{n} m_{j i}+m_{j b}\right) \ddot{u}_{g}
\end{gathered}
$$

where $\mathrm{n}$ is the number of stories of the building; $\mathrm{m}_{\mathrm{b}}, \mathrm{k}_{\mathrm{b}}$ and $\mathrm{c}_{\mathrm{b}}$ are the mass, stiffness and damping of the base, and $m_{j i}$ is the mass of the building $j$ for the $\mathrm{i}^{\text {th }}$ floor.

The general equation of motion for the combination of the seismically isolated building structure and the base slab can be expressed in matrix form as the following [11]:

$$
M^{*} \ddot{X}^{*}+C^{*} \dot{X}^{*}+K^{*} X^{*}=-M^{*} R^{*} \ddot{u}_{g}
$$

where

$$
\begin{array}{rlr}
M^{*} & =\left[\begin{array}{cc}
M & R^{T} M \\
M R & M
\end{array}\right] & R^{*}=\left[\begin{array}{l}
1 \\
0
\end{array}\right] \\
X^{*} & =\left[\begin{array}{c}
u_{b} \\
X^{\prime}
\end{array}\right. & K^{*}=\left[\begin{array}{cc}
k_{b} & 0 \\
0 & K
\end{array}\right]
\end{array}
$$

The equations of motion of the coupled structural system subjected to seismic excitation can be expressed as:

$$
\begin{array}{lr}
\mathrm{M}_{\mathrm{A}} \cdot \ddot{\mathrm{X}}_{\mathrm{A}}(\mathrm{t})+\mathrm{C}_{\mathrm{A}} \cdot \mathrm{X}_{\mathrm{A}}(\mathrm{t})+\mathrm{K}_{\mathrm{A}} \cdot \mathrm{X}_{\mathrm{A}}(\mathrm{t})-\mathrm{f}(\mathrm{t})= \\
-\mathrm{M}_{\mathrm{A}} \cdot \mathrm{I}_{\mathrm{X}}(\mathrm{t}) & (4 \mathrm{a}) \\
\mathrm{M}_{\mathrm{B}} \cdot \ddot{\mathrm{X}}_{\mathrm{B}}(\mathrm{t})+\mathrm{C}_{\mathrm{B}} \cdot \mathrm{X}_{\mathrm{B}}(\mathrm{t})+\mathrm{K}_{\mathrm{B}} \cdot \mathrm{X}_{\mathrm{B}}(\mathrm{t})+\mathrm{f}(\mathrm{t})= \\
-\mathrm{M}_{\mathrm{B}} \cdot \mathrm{I}_{\mathrm{x}}(\mathrm{t}) & (4 \mathrm{~b}) \\
\mathrm{f}(\mathrm{t})=\mathrm{k}_{\mathrm{d}} \cdot \Delta \mathrm{x}_{\mathrm{i}}(\mathrm{t}) & (4 \mathrm{c}) \\
\Delta \mathrm{x}_{\mathrm{i}}(\mathrm{t})=\mathrm{x}_{\mathrm{Bi}}(\mathrm{t})-\mathrm{x}_{\mathrm{Ai}}(\mathrm{t}) & (4 \mathrm{~d})
\end{array}
$$

where $K_{d}, X_{A}$ and $X_{B}$ are the damper stiffness, relative displacement of the building $\mathrm{A}$ and the relative displacement of the building $\mathrm{B}$ for the same floor.

\subsection{Theory of Impact}

In this paper the classical theory of impact, will be taken in the modeling of pounding between the adjacent buildings. This theory based on the laws of conservation of energy and momentum and does not consider transient stresses and deformations in the impacting bodies [7]. The formulae for the post-impact velocities $v_{1}^{\prime}$ and $v_{2}^{\prime}$ of two nonrotating bodies with masses $m_{1}$ and $m_{2}$ in the case of the central impact are given by:

$$
\begin{aligned}
& v_{1}^{\prime}=v_{1}-(1+e) \frac{m_{2} v_{1}-m_{2} v_{2}}{m_{1}+m_{2}} \\
& v_{2}^{\prime}=v_{2}-(1+e) \frac{m_{1} v_{1}-m_{1} v_{2}}{m_{1}+m_{2}}
\end{aligned}
$$

where $v_{1}$ and $v_{2}$ are approaching velocities before impact and $\mathrm{e}$ is a coefficient of restitution which can be obtained from the equation

$$
\begin{gathered}
e=\frac{v_{2}^{\prime}-v_{1}^{\prime}}{v_{1}+v_{2}} \\
C^{*}=\left[\begin{array}{cc}
c_{b} & 0 \\
0 & C
\end{array}\right] \quad M=m_{b}+\sum_{i=1}^{n} m_{i}
\end{gathered}
$$

where $\mathrm{e}=0.5$ to 0.75 for concrete, take it in the modeling $=0.65$ [10].

\subsection{Energy Balance Equation for Multi Degree of Freedom (MDOF) Structures}

The equation of motion of a MDOF structure is written as

$$
M \ddot{u}+C \dot{u}+K u=-M \ddot{u}_{g}
$$

where $\mathrm{M}, \mathrm{C}$, and $\mathrm{K}$ are the mass, damping coefficient, and recovery force, respectively. The integration of the above equation with 
respect to the relative displacement $\mathrm{x}$ leads to the following energy equation Housner [12]:

$$
\begin{array}{r}
\int_{0}^{u} M \ddot{u}_{t} d u+\int_{0}^{u} C \dot{u} d u+\int_{0}^{u} f_{s} d u= \\
-\int_{0}^{u} M \ddot{u}_{g} d u
\end{array}
$$

Using the relationship $d u=\dot{u} d t$, the above equation can be rewritten as follows:

$$
\begin{gathered}
\int_{0}^{u} M \ddot{u}_{t} u d t+\int_{0}^{u} C(\dot{u})^{2} d t+\int_{0}^{u} f_{S} \dot{u} d t= \\
-\int_{0}^{u} M \ddot{u}_{g} \dot{u} d t
\end{gathered}
$$

where the first and the second terms of Eq. 10 represent the kinetic energy $\left(\mathrm{E}_{\mathrm{k}}\right)$ and the damping energy $\left(E_{d}\right)$, respectively, and the third term represents the strain energy $\left(E_{s}\right)$. The right- hand-side of the equation represents the input seismic energy $\left(\mathrm{E}_{\mathrm{i}}\right)$. Therefore the energy balance equation of motion of a MDOF structure is written as

$\mathrm{Ek}+\mathrm{Ed}+\mathrm{Es}=\mathrm{Ei}$

where

$$
\begin{aligned}
& E_{k}=\frac{1}{2} m(\dot{u})^{2}=\frac{1}{2} \dot{u}_{t}^{T} m \dot{u}_{t} \\
& E_{d}=\int_{0}^{t} c \dot{u}^{2} d t=\dot{u}^{T} C \dot{u} \\
& E_{S}=\int_{0}^{t} k \dot{u} d t=\frac{1}{2} u^{T} K u \\
& E_{i}=\int_{0}^{t} m \dot{u}_{g} \dot{u} d t=x^{T} m r
\end{aligned}
$$

\section{RESULTS}

One of the main aims of this study is to investigate the problem of earthquakes induced pounding between two buildings and how to reduce the effect of this phenomenon. Two adjacent base isolated

\begin{tabular}{|c|c|c|c|}
\hline \multicolumn{2}{|l|}{ Building } & Left & Right \\
\hline mass of each story & {$\left[\mathrm{sec}^{2} \mathrm{t} / \mathrm{m}\right]$} & 100 & 50 \\
\hline stiffness of each story & {$[\mathrm{t} / \mathrm{m}]$} & 10000 & 10000 \\
\hline The mass ratio & $\lambda_{b}=\left[m_{b} / m_{t}\right]$ & 0.6 & 0.6 \\
\hline The frequency ratio $\delta$ & $\operatorname{tio} \delta=\left[\omega_{\mathrm{b}} / \omega_{\mathrm{t}}\right]$ & 0.6 & 0.6 \\
\hline Post- pre stiffness $\quad 0$ & $\alpha=\left[\mathrm{K}_{\mathrm{bp}} / \mathrm{K}_{\mathrm{be}}\right]$ & 0.2 & 0.2 \\
\hline \multicolumn{2}{|c|}{ The isolator yield force $(\mathrm{t})$} & 100 & 100 \\
\hline \multicolumn{2}{|c|}{ Structural damping ratio $\quad\left[\zeta_{s}\right]$} & $5 \%$ & $5 \%$ \\
\hline \multicolumn{2}{|c|}{ base damping ratio } & $8 \%$ & $8 \%$ \\
\hline \multicolumn{4}{|c|}{ Connected dampers } \\
\hline $\mathrm{K}_{\mathrm{e}}^{*}$ & \multicolumn{3}{|c|}{$4000 \mathrm{t} / \mathrm{m}$} \\
\hline $\mathrm{F}_{\mathrm{y}} * *$ & \multicolumn{3}{|c|}{10 ton } \\
\hline$\alpha$ & \multicolumn{3}{|c|}{0.0} \\
\hline \multicolumn{4}{|c|}{ Sinusoidal wave } \\
\hline$\omega_{\mathrm{ex}}$ & \multicolumn{3}{|c|}{$3.0 \mathrm{rad}$} \\
\hline$t_{\max }$ & \multicolumn{3}{|c|}{$20 \mathrm{sec}$} \\
\hline
\end{tabular}
buildings $2 \mathrm{DOF}$ are idealized as lumped mass with viscous damper connected the two buildings at all levels are analyzed, as shown in Fig. 1, in order to study the pounding control. The basic parameters of such model with initial values where shown in Table 1.

Table (1) Properties of the studied buildings

*Elastic stiffness of the damper.

** Yield force.

Fig. 2 shows the displacement time history of the two buildings for the controlled and uncontrolled case when subjected to harmonic excitation with frequency equal to $3.0 \mathrm{rad}$ for time equal $20 \mathrm{sec}$. It is shown that, the peak displacement decreases with the laying of the connected link between the two buildings. The peak absolute displacement of the top story of the reference building A reduces from 37.05 $\mathrm{cm}$ to $28.86 \mathrm{~cm}$ with reduction factor equals $22 \%$. Also, the peak displacement of the upper story of the building B reduces from $37.66 \mathrm{~cm}$ to $21.1 \mathrm{~cm}$ with reduction factor equals $44 \%$. Also on the other hand, the total energy decreases from $5.63 * 10^{5}$ t. m to $4.83 * 10^{5}$ t. m with reduction factor $14.2 \%$ as shown in Table 2. This reduction in the total energy occurs due to the absorption of the pounding force in the linked damper, and this can be attributed to the large stiffness of the connecting link in all cases which make the buildings behaves as 
one building. Also, this can shift the natural frequencies of the structures away from the dominant frequency of the ground motion.
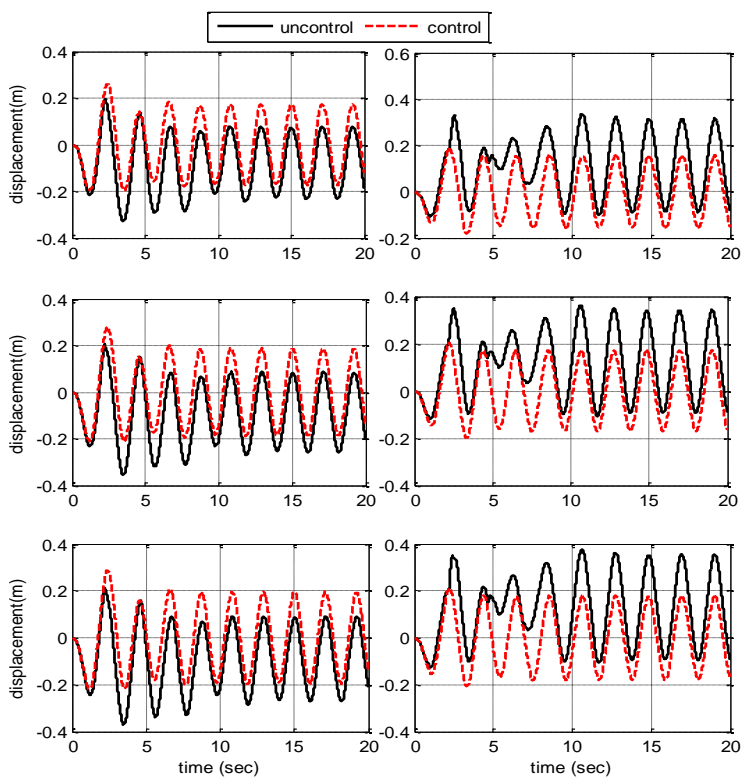

Fig. 2: Uncontrolled vs. controlled floor disp.

$(a, b, c)$ results for building $A,(d, e$, and f) results for building $B$.

Table 2: Max. displacement and total energy for the two cases

\begin{tabular}{|c|c|c|c|}
\hline \multicolumn{2}{|c|}{ building } & $\begin{array}{c}\text { Left } \\
\text { building }\end{array}$ & $\begin{array}{l}\text { Right } \\
\text { building }\end{array}$ \\
\hline \multirow{2}{*}{$\begin{array}{l}\text { sliding disp. } \\
\text { of base }(\mathrm{cm})\end{array}$} & controlled & 26.26 & 18.34 \\
\hline & uncon & 32.95 & 33.66 \\
\hline \multirow{2}{*}{$\begin{array}{c}\text { First floor } \\
\text { disp. abs }(\mathrm{cm})\end{array}$} & contrc & 27.99 & 20.07 \\
\hline & uncontrolled & 35.56 & 36.35 \\
\hline \multirow{2}{*}{$\begin{array}{l}\text { Second floor } \\
\text { disp. abs. }(\mathrm{cm})\end{array}$} & controlled & 28.86 & 21.10 \\
\hline & uncontrolled & 37.05 & 37.66 \\
\hline \multicolumn{3}{|c|}{ Total energy (uncontrolled) $* 10^{5}$ t.m } & 5.6330 \\
\hline \multicolumn{3}{|c|}{ Total energy (controlled) $* 10^{5}$ (t.m) } & 4.8562 \\
\hline
\end{tabular}

The way to determine the optimum parameters of the dampers used to link the two adjacent buildings are discussed in this section using the principle of minimizing the total vibration energy. Fig. 3 shows the total energy as a function of a variable sinusoidal excitation frequencies and yield displacement of the connected dampers $\mathrm{x}_{\mathrm{y}}$. This Figure shows the maximum value of the transmitting has been occurred at $\omega_{\mathrm{ex}}$ equals $2.0 \mathrm{rad}$ which indicates the resonance range. This value of the harmonic frequency will be used in the following study of the parameters effect of the damper on the pounding control. Fig. 3(c) shows the relation between the energy ratio and the yield force at $\omega_{\mathrm{ex}}$ equals $2.0 \mathrm{rad}$. The energy transmitted has been decreased with the increase in the yield force because the damper still in the elastic case for a long time, which gives more efficient in the pounding control.
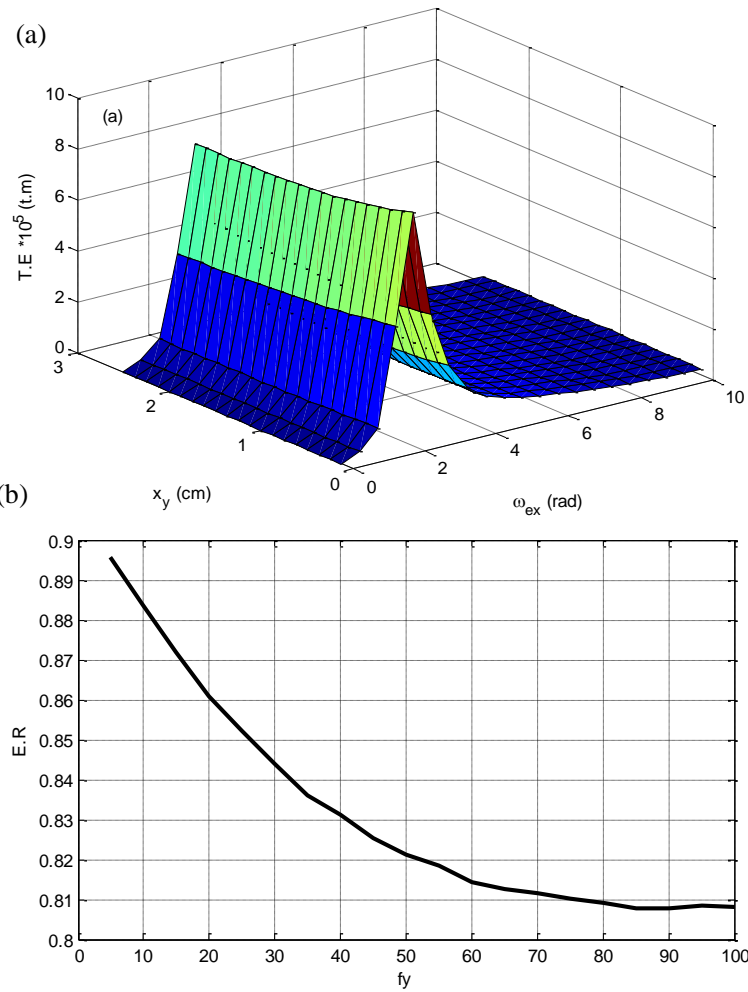

Fig. 3: The total energy versus excitation frequency and yield disp. (a) surface area, and (b) the energy ratio (controlled energy /uncontrolled energy) at $w_{\mathrm{ex}}=2.0 \mathrm{rad}$.

\subsection{Effect of Changing Viscous Damper Parameters:}

The effect of changing the connected damper parameters on the control system will be studied. The parameters used in the operation of the study are the post-pre 
stiffness ratio, elastic stiffness and the yield force of the link material.

\subsubsection{Effect of Natural Frequencies of the Adjacent Buildings:}

Figs. 4 to 7 introduce the effect of the variation of the natural frequency of the two adjacent buildings, yield displacement $\mathrm{x}_{\mathrm{y}}$ and the elastic stiffness of the connected damper $\mathrm{k}_{\mathrm{d}}$ on the total transmitting energy. These figures show that, by increasing the natural frequency of the adjacent structures, the relative displacement and velocity in all floor levels increase which increases the force in the link and makes the required dissipation energy increased. This increase in the dissipation energy must take smaller value of yield force that makes the damper enter in the plastic stage rabidly and the energy confined in the force displacement curve of the damper increases, as shown in Fig. 8. Also from these figures, the decrease in the total energy transmitted to the structures in the direction of increasing of the damper stiffness at the yield force that minimize the total energy, decreased slowly after certain value that almost equal $0.6 * 10^{4}$ $\mathrm{t} / \mathrm{m}$ from the reference building stiffness $A$. so, the increase in the stiffness of the damper after this point will not be cost-effective.
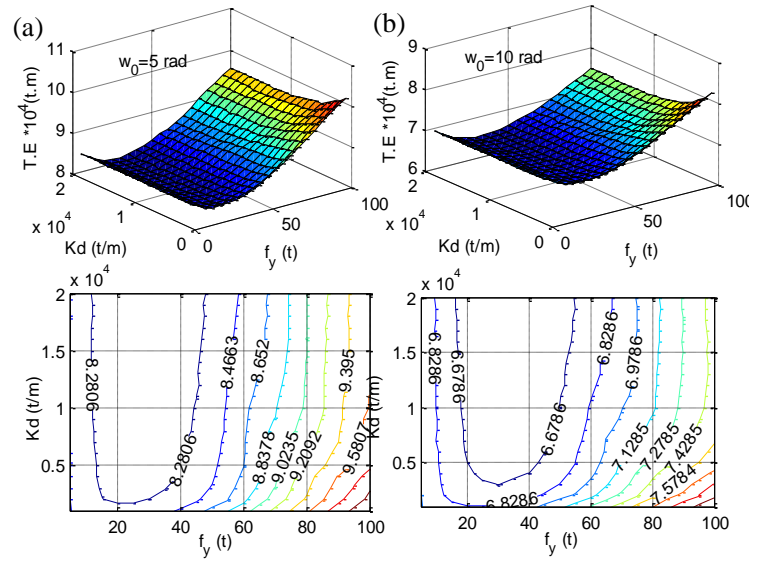

Fig. 4: Total energy with yield force and damper stiffness (a) $\omega_{0}=5.0 \mathrm{rad}$, and (b) $\omega_{0}=10.0 \mathrm{rad}$.
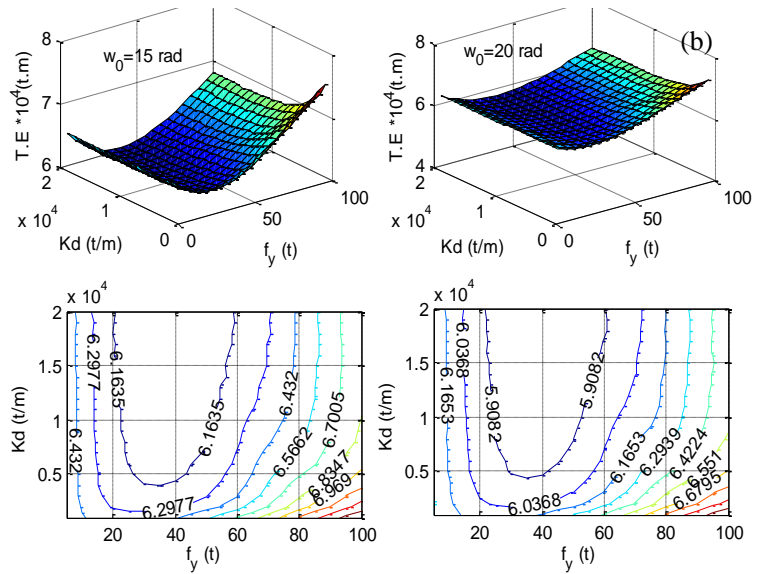

Fig. 5: Total energy with yield force and damper stiffness (a) $\omega_{0}=15.0 \mathrm{rad}$, and (b) $\omega_{0}=20.0 \mathrm{rad}$.
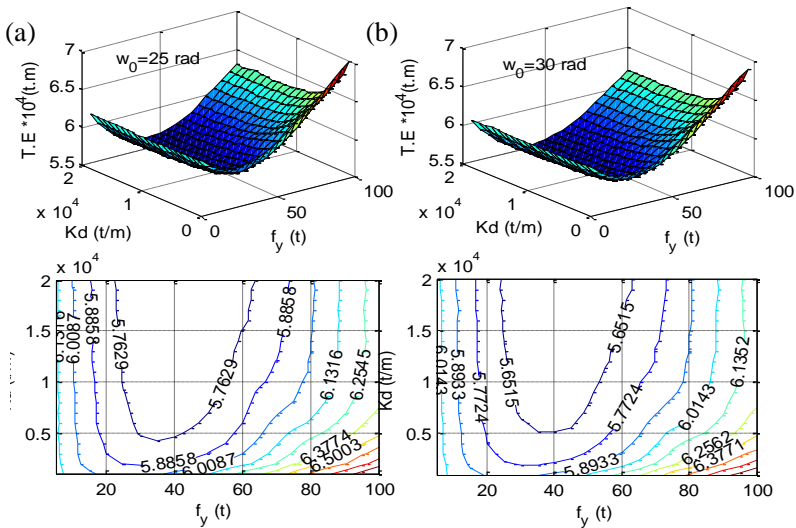

Fig. 6: Total energy with yield force and damper stiffness (a) $\omega_{0}=25.0 \mathrm{rad}$, and (b) $\omega_{0}=30.0 \mathrm{rad}$.

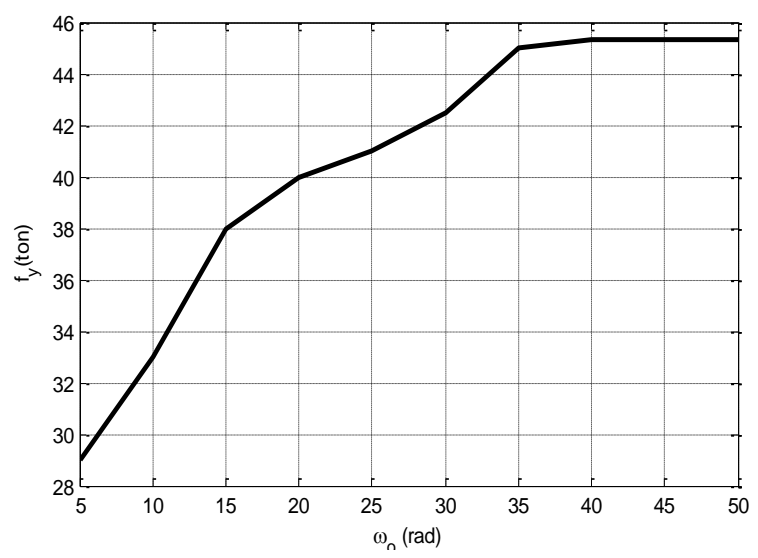

Fig. 7: natural frequency of structures and yield displacement which minimize transmitted energy.

(a) 


\subsubsection{Effect of Post-Pre Stiffness Ratio:}

Fig. 8 presents the total energy of the two adjacent buildings, as a function of elastic stiffness ratio $k_{d}$ and the post-pre stiffness ratio of the damper $\alpha$ of the connected damper. The values of post stiffness ratio will be taken from 0.0 to 1.0 and for elastic stiffness from 0.0 to $20,000 t / \mathrm{m}$. This figure shows that, the total energy transmitting decreases with the increase in the post stiffness ratio until the value which gives small increases in the total energy. This because, the increase in the stiffness of the damper make the two buildings behaves as one building to a certain value after that it will be cost effective. In the other hand, the total energy decreases with the decrease in the post stiffness ratio of the damper until the best value at post value equal zero, because the decrease in the post stiffness increases the area of confined in the forcedisplacement curve which increases the dissipation energy.
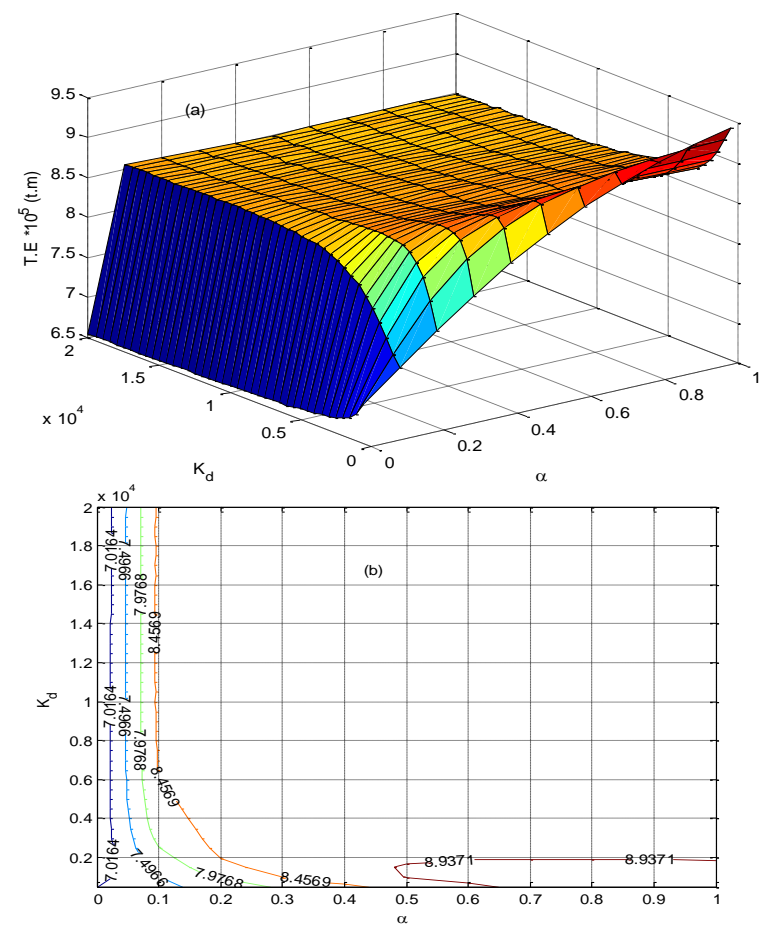

Fig. 8: Total energy wirh damper stiffness and post stiffness, (a) surface area ,(b) contour line.

\subsubsection{Effect of Buildings Natural Frequency:}

Fig. 9 shows the effect of the natural frequency of building $\mathrm{A}$ and yield displacement $\mathrm{x}_{\mathrm{y}}$ of the connected dampers on the total energy. While the ratio between the natural frequencies of the two adjacent building remains constant. Also, the values of natural frequency will be taken from 10 $\mathrm{rad}$ to $20 \mathrm{rad}$ and for yield displacement from $0 \mathrm{~cm}$ to $2.5 \mathrm{~cm}$. It is clear that, the total energy transmitted to the superstructure part decreases with the increase in the natural frequency of the adjacent structures. This can be attributed to the idea of the increase in the natural frequency of the adjacent buildings decreases the interstory displacement of the buildings which makes the required control force decreases and decreases the transmitted energy.
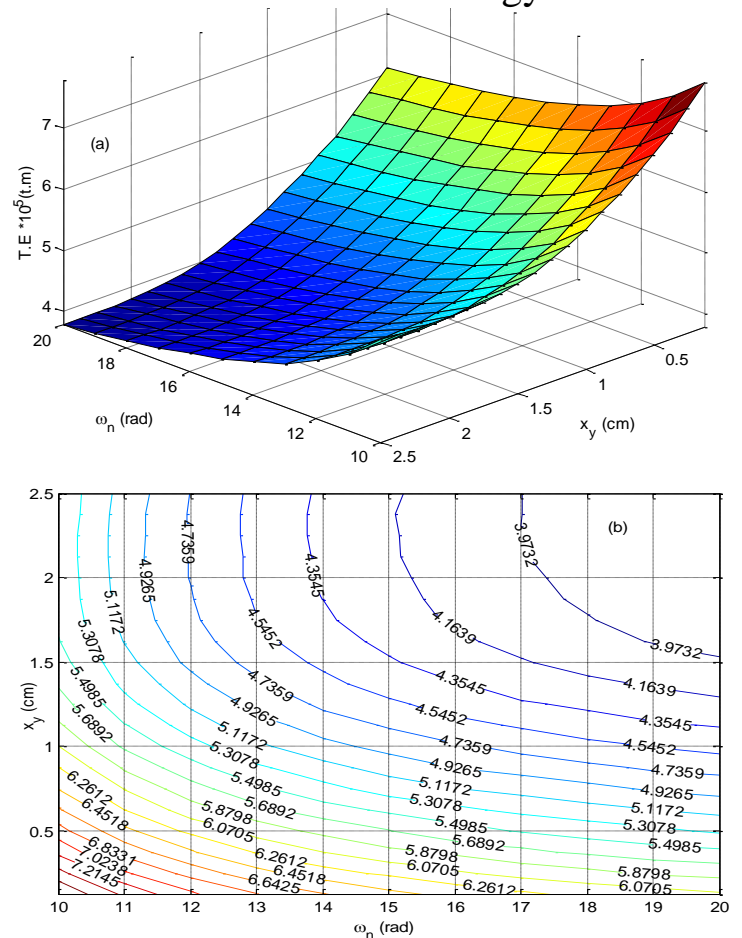

Fig. 9: Total energy with natural frequency and yield disp. (a) surface area, (b) contour line.

\section{CONCLUSIONS}

In this study, a mathematical modeling of adjacent building pounding has been 
demonstrated and its implementation in a MATLAB program seismic analysis is presented. Numerical investigation, aiming to make the comparison between the earthquakes induced pounding involved behaviors of the two adjacent buildings modeled many points can be concluded from this research:

1- The total displacement decreases with using the viscous dampers in the space between the adjacent buildings as shown in table 2, also the total transmitted energy decreased by $14 \%$.

2- The total transmitted energy decreased with the decrease in the post stiffness ratio of the viscous dampers due to the increase in the dissipation energy.

3- The total transmitted energy decreased with the increase in the yield displacement of the viscous dampers to a certain point and the increased due to the increase in the dissipation energy at the beginning and retain to the decreasing again.

4- When the natural frequency of the adjacent buildings increased the yield force of the damper which minimize the total transmitted energy with $50 \%$.

5- The total energy decreased with the increase in the elastic stiffness at the beginning and almost will be constant due to the two buildings behaves as one buildings after that.

\section{REFERENCES}

[1] Hao, H. and Zhang, S. R., 1999 "Spatial ground motion effect on Relative displacement of adjacent building structures", Earthquake Eng Struct Dyn; 28: 333-49; International Building Code.

[2] Komodromos, P. I., 2005 "Influence of Earthquake-Induced Poundings on the Effectiveness of Seismic Isolation", Department of Civil Engineering.

[3] Anagnostopoulos. S. A. and spiliopoulos. K. V., 1992 "Earthquake Induced Pounding in Adjacent Buildings", earthquake engineering, Tenth World Conference, pp 3878-3892.
[4] Chau, K. T., Wei, X. X., Guo, X. and Shen. C. Y., 2003 "Experimental and Theoretical Simulations of Seismic Poundings Between Two Adjacent Structures", Earthquake Engineering and Structural Dynamics; 32 : 537 -554.

[5] Chopra A. K., Dynamics of structures: Theory and applications to earthquake engineering, Englewood Cliffs (NJ): PrenticeHall.

[6] Nawawi, C. and HAO, H., 2004 "Reduction of Pounding Responses of Bridges Girders with Soil-Structure Interaction Effects To Spatial Near-Source Ground Motions", 13 World Conference on Earthquake Engineering Vancouver, B.C., Canada 1-6, Paper No. 1350.

[7] Orlando, C. and Luis, E. S., 2008 "Numerical Investigation of a Variable Damping Semiactive Device for the Mitigation of the Seismic Response of Adjacent Structures", ComputerAided Civil and Infrastructure Engineering 23 291-308.

[8] Jankowski, R., Wilde, K. and Fujino, Y., 1999 "reduction of pounding effects in elevated bridges during earthquakes", Earthquake Engineering Structure Dynamics 2000; 29: 195212

[9] Math Works, MATLAB: The Language of Technical Computing, the Math Works, Inc., Natick, MA (2009).

[10] Jankowski, R., 2005, 'Non-linear viscoelastic modeling of earthquake- induced structural pounding', Earthquake Engineering and Structural Dynamics, pp. 595-616.

[11] Naeim, F. Kelly, J. M., 1999 "Design of Seismic Isolated Structures", John Wiley \& Sons.

[12] Housner, G.W., 1956 "Limit Design of Structures to Resist Earthquakes", Proceedings of the 1st World Conference on Earthquake Engineering, Berkeley, CA, USA. 